\title{
Oil Prices and Stock Markets in Europe: Detection of Extreme Risk Spillover
}

\author{
Blanka kęt ${ }^{1}$ \\ ${ }^{1}$ Poznań University of Economics and Business \\ Department of Applied Mathematics \\ Al. Niepodległości 10, 61-875 Poznań, Poland \\ E-mail: blanka.let@ue.poznan.pl
}

\begin{abstract}
The goal of this paper is to check the existence of Granger causality in risk between eleven European stock markets and the crude oil market. We analyze bidirectional instantaneous and delayed Granger causality in tails test results, i.e. whether occurrence of the extreme returns on the crude oil market precede similar events on the main European stock markets and vice versa. Our analysis is devoted to the short-run period. Using Brent futures prices and main stock indices in Europe (Belgium, France, Germany, Greece, Italy, Netherlands, Norway, Poland, Spain, Sweden, and United Kingdom), we apply the testing procedure developed by Candelon and Tokpavi (2016). The main conclusion is that in the vast majority of cases instantaneous causality in tails was symmetrical. We also found that more long-lived reactions appeared as a result of negative news from the oil market and from the stock markets.
\end{abstract}

Keywords: risk spillover, crude oil, stock market, extreme value, Granger causality

JEL codes: G15, Q02, C12

\section{Introduction}

Crude oil is a unique commodity, crucial for the global economy. Black gold has countless uses; transport sector, chemical sector, agriculture depend on the access to oil. Investors and market participants closely monitor the price of oil. This price is a crucial factor for importers and exporters. Oil dependent companies in importing countries bear higher costs when the price increases. On the other hand, oil producers monitor oil futures price, which can vary as a result of changing demand. When the economy slows down and oil-using industries are in crisis, it may lead to a lower oil demand. Unexpected jumps in oil futures price could be treated by market participants as a signal of a changing economic condition. On the other hand, investors from oil importing or exporting countries can have different opinions about a possible effect of raising or falling oil price on their national economy.

In this paper, we propose to apply Candelon and Tokpavi (2016) test to detect the existence of extreme risk spillover between oil market and stock markets in Europe. It should be noted that we employ this test to examine daily data properties, so our analysis is devoted rather to the short-run period. The paper is organized as 
follows. In the first section, we describe selected previous works devoted to oilstock markets relation. The data and testing procedure are detailed in Section 2. Section 3 contains empirical results and the last part of the article brings conclusions.

\section{Literature Review}

There are numerous empirical studies dealing with the relationship between oil and stock markets. Probably the most important early studies were conducted by Jones and Kaul (1996), Huang et al. (1996) and Sadorsky (1999). Using GARCH model and VAR framework, Sadorsky (1999) found that oil price and volatility affect real stock returns.

Maghyereh et al. (2016) studied the connectedness between the oil implied volatility and the implied volatility of equities in eleven major equity markets (USA, Canada, Japan, United Kingdom, Germany, Russia, Sweden, Switzerland, India, South Africa, and Mexico). They found that oil market plays the dominant role in the oil equity volatility relationship.

On the other hand, Zhang (2017) studied the relationship between oil shocks and returns at six major stock markets around the world (US, UK, Germany, Japan, Singapore, China) using a measure of connectedness and concluded that oil shocks may be important to a single market, but only big shocks matter to the global financial system.

Previous works devoted to the oil and stock market relation highlighted an importance of the distinction between oil importing and oil exporting countries. Wang et al. (2013) found that magnitude, duration and direction of effects of oil price shocks on stock markets highly depend on whether the country is a net importer or exporter. Basher et al. (2018) examined the impact of oil price shocks on stock markets in eight oil exporting countries (Canada, Norway, United Kingdom, Saudi Arabia, Mexico, Russia, Kuwait, and United Arab Emirates) in a multi-factor two-state Markov-switching framework. They found that oil-market shocks affect stock markets in most of the oil exporting countries studied. Jammazi et al. (2017) analyzed time-varying causal linkages in mean and variance between oil price changes and stock returns for six major oil importing countries (France, Germany, Italy, Spain, the UK, and the US). They found bidirectional causal relations for all countries.

A number of approaches and methods have been proposed in earlier studies on European stock markets - oil relation analysis. Park and Ratti (2008) conducted multivariate VAR analysis of monthly data from Austria, Belgium, Denmark, Finland, France, Germany, Greece, Italy, Netherlands, Norway, Spain, Sweden, and United Kingdom. They estimated the effect of oil price shocks and concluded that they have an impact in the same month or within one month. Furthermore, they found that high volatility on the oil market depresses real stock returns. 
Arouri (2011) applied multifactor model with GARCH specification to weekly data to examine the responses of European sector stock markets to oil price changes. The companies represented largest companies in Austria, Belgium, Denmark, Finland, France, Germany, Greece, Iceland, Ireland, Italy, Luxembourg, Netherlands, Norway, Portugal, Spain, Sweden, Switzerland, and the United Kingdom. The main conclusion from this study is that strength of linkages depends on the type of sector of the economy.

Arouri et al. (2012) estimated bivariate VAR-GARCH model to investigate dependencies between Dow Jones Stoxx Europe 600 index, seven sector indices and oil prices using weekly data. They found that there is a significant volatility spillover between sector stock returns and oil returns.

Śmiech and Papież (2013) found existence of Granger causality between weekly DAX returns and Brent oil in the period of high volatility using Toda and Yamamoto methodology.

Wanat et al. (2015) conducted causality in distribution test based on empirical copula. Using daily data from Germany and United Kingdom, they found that there was a contemporaneous causality in distribution between crude oil and analyzed indices only in selected periods.

Our work contributes to previous research on European stock market-crude oil relation. First of all, to the best of our knowledge, Candelon and Tokpavi (2016) test has never been used before for European stock markets - oil relation analysis. Secondly, we use daily data to check whether extreme risk spillover occurs on the same day or within few days after the shock. The third aspect of our work is that we analyze results of bidirectional linkages, i.e. the existence of Granger causality in risk between oil and stock markets in both directions.

\section{Data and Methods}

\subsection{Data}

In this paper we analyze daily prices of major European indices (Belgium: BEL20, France: CAC40, Germany: DAX, Greece: ATH, Italy: FMIB, Netherlands: AEX, Norway: OSEAX, Poland: WIG20, Spain: IBEX, Sweden: OMX30, United Kingdom: FTSE250) and Brent oil futures prices, the most important benchmark for oil prices in Europe.

Countries we have chosen are the largest net importers of oil in Europe. Norway is an exception, it is an oil net exporter. According to the data in BP Statistical Review of World Energy (2018), the countries analyzed have diverse oil's share in primary energy mix. The largest share is in Greece (56.16\%) and Belgium (51.69\%). Other countries also use oil intensively: Netherlands: $47.39 \%$, Sweden: $46.69 \%$, Spain: 41.29\%, United Kingdom: 39.88\%, Italy: 38.85\%, Germany: 35.75\%, France: $33.5 \%$, Poland: $30.95 \%$, Norway: $21.26 \%$, so the price of oil is an important factor to the their national economy. The scope of our analysis is also well-founded due 
to the significant role of the stock exchanges in these countries, a big component of the global financial market.

We analyze the data from the last eleven years from January 2, 2008, until April 30,2019 . We use daily percentage logarithmic returns defined as $r_{t}=100 \cdot \ln \frac{P_{t}}{P_{t-1}}$, where $P_{t}$ denotes the price of an asset at time $t$.

\subsection{Testing Procedure}

There are several methods of testing Granger causality. For example, Cheung and $\mathrm{Ng}$ (1996) and Hong (2001) introduced Granger causality test in variance. Hong et al. (2009) proposed Granger causality test in risk, which allows detecting lead-lag relationship between extreme events in the distribution tails for a pre-specified risk level.

We consider two time series, $X_{t}$ and $Y_{t}$. If $\operatorname{VaR}_{t}^{X_{-} \text {long }}(\alpha)$ and $\operatorname{VaR}_{t}^{X_{-} \text {short }}(\alpha)$ denote a risk measure Value at Risk at level $\alpha$ for long and short trading position, then

$$
\begin{aligned}
& P\left(X_{t}<-\operatorname{VaR}_{t}^{X_{-} \text {long }}(\alpha) \mid \mathcal{F}_{t-1}^{X}\right)=\alpha, \\
& P\left(X_{t}>\operatorname{VaR}_{t}^{X_{-} \text {short }}(\alpha) \mid \mathcal{F}_{t-1}^{X}\right)=1-\alpha,
\end{aligned}
$$

where $\mathcal{F}_{t-1}^{X}$ is the information set:

$$
\mathcal{F}_{t-1}^{X}=\left\{X_{t-j}, j=1,2, \ldots\right\} .
$$

Hong et al. (2009) causality in risk test determines whether Value at Risk violation for $Y_{t}$ can be considered as a lagged indicator of a similar situation for $X_{t}$. They define tail event variables $Z_{t}^{X}$ and lagged $Z_{t}^{Y}$ defined as

$$
\begin{aligned}
& Z_{t}^{X}=\left\{\begin{array}{ccc}
1 & \text { if } & X_{t}<-\operatorname{VaR}_{t}^{X_{-} l o n g}(\alpha) \\
0 & \text { otherwise }
\end{array}\right. \\
& Z_{t}^{Y}=\left\{\begin{array}{ccc}
1 & \text { if } & Y_{t}<- \text { VaR }_{t}^{Y \_l o n g}(\alpha) \\
0 & \text { otherwise, }
\end{array}\right.
\end{aligned}
$$

Using the sample cross-correlation function between these event variables, they construct a test statistic with a large number of lags and higher-order lags discounted. Similarly, to the idea described in Hong (2001) causality in variance test, Hong et al. (2009) proposed to use a kernel weighting function to reflect the fact that older news have a smaller influence on current market trends than more recent market data.

The Candelon and Tokpavi (2016) test is a multivariate extension of the abovementioned tests. It checks the existence of Granger causality between the multivariate processes of event variables for a selected region of the distribution. It can be used to detect causality in the whole distribution or to check for Granger causality in specific regions on the distribution, such as the center or tails. 
Consider a set $A=\left\{\alpha_{1}, \ldots, \alpha_{m}\right\}$ of $m$ VaR risk levels. For the left tail one can choose $A=\{1 \%, 5 \%, 10 \%\}$, for the right tail $A=\{90 \%, 95 \%, 99 \%\}$. Then divide tails into $m$ disjoint regions each related to the indicator or event variable.

For the left tail, we define the following event variables:

$$
\begin{aligned}
& Z_{t, 1}^{X}=\left\{\begin{array}{rrr}
1, & \text { if } & X_{t}<-V a R_{t}^{X \_l o n g}\left(\alpha_{1}\right) \\
0, & \text { otherwise, }
\end{array}\right.
\end{aligned}
$$

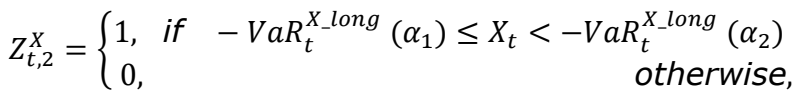

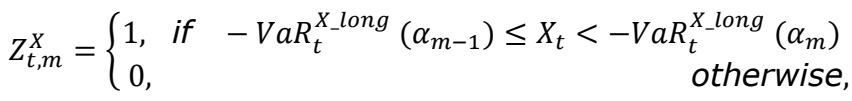

For the right tail, we define the following event variables:

$$
\begin{aligned}
& Z_{t, 1}^{X}=\left\{\begin{array}{rr}
1, & \text { if } \\
0, & \operatorname{VaR}_{t}^{X_{-} \text {short }}\left(\alpha_{1}\right)<X_{t} \leq \operatorname{VaR}_{t}^{X_{-} \text {short }}\left(\alpha_{2}\right)
\end{array}\right. \\
& \text {.. } \\
& Z_{t, 2}^{X}=\left\{\begin{array}{rrr}
1, & \text { if } & \operatorname{VaR}_{t}^{X_{-} \text {short }}\left(\alpha_{m-1}\right)<X_{t} \leq \operatorname{VaR}_{t}^{X \_ \text {short }}\left(\alpha_{m}\right) \\
0, & \text { otherwise, }
\end{array}\right.
\end{aligned}
$$

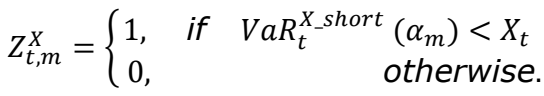

Let $\boldsymbol{H}_{t}^{X}=\left(Z_{t, 1}{ }^{X}, Z_{t, 2}{ }^{X}, \ldots, Z_{t, m}{ }^{X}\right)^{T}$ and $\boldsymbol{H}_{t}^{Y}=\left(Z_{t, 1}{ }^{Y}, Z_{t, 2}{ }^{Y}, \ldots, Z_{t, m}{ }^{Y}\right)^{T}$ be a column vectors of dimension $\mathrm{m}$. Time series $Y_{t}$ does not Granger-cause time series $X_{t}$ in tail if the following hypothesis holds:

$$
H 0: E\left(\boldsymbol{H}_{t}^{X} \mid \mathcal{F}_{t-1}^{X \& Y}\right)=E\left(\boldsymbol{H}_{t}^{X} \mid \mathcal{F}_{t-1}^{X}\right)
$$

where $\mathcal{F}_{t-1}^{X \& Y}=\left\{X_{t-j}, Y_{t-j}, j=1,2, \ldots\right\}$.

Candelon and Tokpavi (2016) proposed the following test statistic:

$$
V_{Y \rightarrow X}=\frac{\hat{T}-m^{2} C(M)}{\sqrt{m^{2} D(M)}}
$$

where 


$$
\begin{aligned}
& \hat{\mathcal{T}}=\sum_{j=1}^{T-1} k^{2}\left(\frac{j}{M}\right) \hat{Q}(j), \\
& \hat{Q}(j)=T \operatorname{vec}(\widehat{\boldsymbol{R}}(j))^{T}\left(\widehat{\boldsymbol{\Gamma}}_{X}^{-1} \otimes \widehat{\boldsymbol{\Gamma}}_{Y}^{-1}\right) \operatorname{vec}(\widehat{\boldsymbol{R}}(j))
\end{aligned}
$$

and $\widehat{\boldsymbol{R}}(j)$ is the sample cross-correlation matrix between $\boldsymbol{H}_{t}^{Y}$ (lagged by $j$ ) and $\boldsymbol{H}_{t}^{X}$, $\hat{\boldsymbol{\Gamma}}_{X}$ is the sample correlation matrix of $\boldsymbol{H}_{t}^{X} ; k$ is the kernel function, $M$ is the truncation parameter, $T$ is the length of the sample, $C(M)$ and $D(M)$ are location and scale parameters:

$$
\begin{aligned}
& C(M)=\sum_{j=1}^{T-1}\left(1-\frac{j}{T}\right) k^{2}\left(\frac{j}{M}\right), \\
& D(M)=2 \sum_{j=1}^{T-1}\left(1-\frac{j}{T}\right)\left(1-\frac{j+1}{T}\right) k^{4}\left(\frac{j}{M}\right) .
\end{aligned}
$$

There are several possible kernel functions:

- Bartlett kernel function

$$
k(z)=\left\{\begin{array}{cc}
1-|z|, & |z|<1 \\
0, & |z| \geq 1
\end{array},\right.
$$

- Daniell kernel function

$$
k(z)=\left\{\begin{array}{cc}
1, & z=0 \\
\frac{\sin (\pi z)}{\pi z}, & z \neq 0
\end{array},\right.
$$

- Parzen kernel function

$$
k(z)=\left\{\begin{array}{cc}
1-6 z^{2}+6|z|^{3}, & |z|<0,5 \\
2(1-|z|)^{3}, & 0,5 \leq|z|<1, \\
0, & |z| \geq 1
\end{array}\right.
$$

- QS kernel function

$$
k(z)=\left\{\begin{array}{cc}
1, & z=0 \\
\frac{3}{\sqrt{5}(\pi z)^{2}}\left\{\frac{\sin (\pi z)}{\pi z}-\cos (\pi z)\right\}, & z \neq 0
\end{array},\right.
$$

- Tukey-Hanning kernel function

$$
k(z)=\left\{\begin{array}{cc}
\frac{1}{2}(1+\cos (\pi z)), & |z|<1 \\
0, & |z| \geq 1
\end{array} .\right.
$$

Hong et al. (2009) and Candelon and Tokpavi (2016) suggest that the choice of kernel gives comparable results. Under the null hypothesis of no Granger causality in tails, test statistic $V_{Y \rightarrow X}$ converges in distribution to a standard normal random 
variable. There are many ways to determine the Value at Risk forecasts. In this analysis, we compute mean and volatility forecasts obtained from ARMA-GARCH family of models to estimate Value at Risk for a pre-specified risk level.

\section{Results and Discussion}

Table 1 contains information about basic descriptive statistics. The mean value of daily percentage logarithmic returns is close to zero. High excess kurtosis suggests non-normal, fat-tailed distribution of returns, which is typical for financial time series. Volatility measured by standard deviation is moderate. Figure 1 presents the dynamics of the analyzed series. In the last eleven years, volatility levels of all series changed over time. One can see volatility clustering characteristic for financial time series, also known as the ARCH (Autoregressive Conditional Heteroskedasticity) effect. Therefore, it is reasonable to use ARMA-GARCH family of models to determine Value at Risk forecasts. Table 2 shows models selected for particular time series.

Table 1 Descriptive Statistics

\begin{tabular}{ccccc}
\hline & Mean & $\begin{array}{c}\text { Std. } \\
\text { deviation }\end{array}$ & Skewness & Excess kurtosis \\
\hline \hline AEX & 0.0040 & 1.3493 & -0.2110 & 8.4548 \\
\hline DAX & 0.0059 & 1.6477 & 0.0137 & 7.6631 \\
\hline FMIB & -0.0192 & 1.6847 & -0.2009 & 4.6562 \\
\hline IBEX & -0.0155 & 1.5532 & -0.0854 & 7.1800 \\
\hline CAC40 & 0.0002 & 1.4426 & -0.0076 & 6.5276 \\
\hline FTSE & 0.0217 & 1.1269 & -0.4327 & 5.0284 \\
\hline BEL20 & -0.0033 & 1.2741 & -0.1505 & 6.2049 \\
\hline WIG20 & -0.0135 & 1.4274 & -0.2951 & 3.8824 \\
\hline ATH & -0.0683 & 2.1457 & -0.3028 & 5.3095 \\
\hline OMX30 & 0.0162 & 1.4001 & 0.0110 & 5.3373 \\
\hline OSEAX & 0.0197 & 1.4510 & -0.6182 & 7.1161 \\
\hline Brent & -0.0108 & 2.1343 & 0.0092 & 3.7414 \\
\hline
\end{tabular}

Source: Author's own calculations. 
Figure 1 Daily Returns of Crude Oil and Stock Market Indices
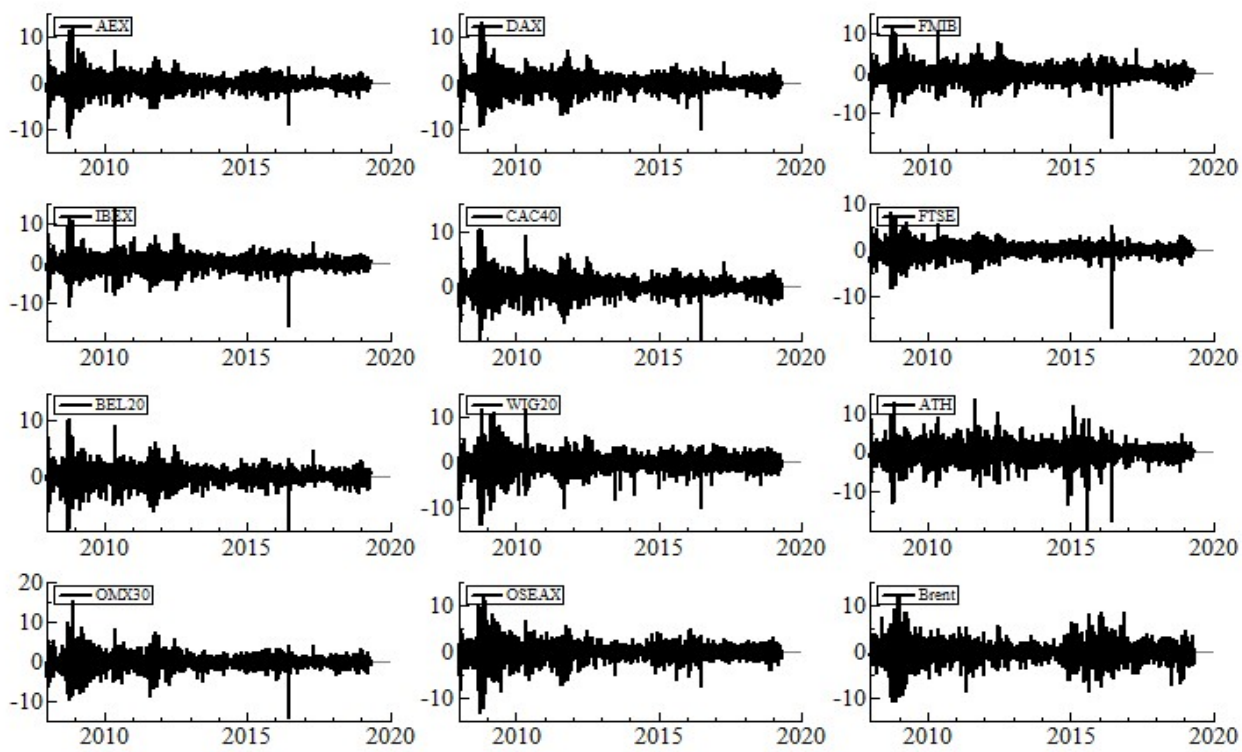

Source: Author's own elaboration.

Table 2 Fitted ARMA-GARCH Models

\begin{tabular}{ccc}
\hline & Model & Distribution \\
\hline AEX & $\operatorname{GARCH}(1,1)$ & Skewed Student \\
\hline DAX & $\operatorname{GARCH}(1,1)$ & Skewed Student \\
\hline FMIB & $\operatorname{AR}(1)-\operatorname{GARCH}(1,1)$ & Skewed Student \\
\hline IBEX & $\operatorname{APARCH}(1,1)$ & Skewed Student \\
\hline CAC40 & $\operatorname{AR}(1)-\operatorname{GARCH}(1,1)$ & Skewed Student \\
\hline FTSE & $\operatorname{AR}(1)-\operatorname{GARCH}(1,1)$ & Student \\
\hline BEL20 & $\operatorname{GARCH}(1,1)$ & Skewed Student \\
\hline WIG20 & $\operatorname{AR}(1)-\operatorname{APARCH}(1,1)$ & Student \\
\hline ATH & $\operatorname{AR}(1)-\operatorname{GARCH}(1,1)$ & Student \\
\hline OMX30 & $\operatorname{AR}(1)-\operatorname{GARCH}(1,1)$ & Student \\
\hline OSEAX & $\operatorname{GARCH}(1,1)$ & Student \\
\hline Brent & $\operatorname{AR}(1)-\operatorname{GARCH}(1,1)$ & \\
\hline
\end{tabular}

Source: Author's own elaboration. 
We applied Candelon and Tokpavi testing procedure in the analyzed period. The test results of Granger causality in tails are reported in Tables 3-6. First, we check if there is an instantaneous and delayed causality in risk. Complementing Equation (9) with values of $\hat{Q}(j)$ when $j=0$ one can test whether extreme movements, past or current, in one market may have a significant predictive power for those in the second market. Thus we can test whether extreme risk on the oil market coexisted with the risk on stock markets and possibly whether there was a delay in the reaction of market participants. Testing results are reported in Tables 3 and 4 . We are testing if Granger causality in tails exists within ten days, setting truncation parameter $M=11$.

We received very interesting and significant results. In most cases, symmetrical causality was dominant, i.e. extreme negative or positive returns on the oil market and stock markets had the same direction. Investors may perceive price jumps as a signal of a changing economic situation. Dominant reaction to extremely low oil prices was that stock markets fall and vice versa. We can explain our findings by taking into account the fact that after global financial crisis, all markets are more connected and symmetrical price movements occur as a result of financialization in commodity markets.

The days when the reaction was asymmetrical also occurred, but less frequently. Only in the case of Greek investors, there was a dominant asymmetrical response to the extreme positive returns on the oil market. As we mentioned before, crude oil is the most important source of primary energy in Greece. High oil prices are more troublesome for Greek economy, so our testing results show that market participants in Greece may perceive extremely high oil prices as a threat to their national economy.

Table 3 P-values of Granger Contemporaneous and Delayed Causality in Tails Test (Oil $\rightarrow$ Stock Market). Full Sample: 2.01.2008-30.04.2019

\begin{tabular}{ccccc}
\hline \multirow{2}{*}{ Country } & \multicolumn{4}{c}{ Type of tails tested } \\
\cline { 2 - 5 } & Left $\rightarrow$ Left & Left $\rightarrow$ Right & Right $\rightarrow$ Right & Right $\rightarrow$ Left \\
\hline \hline Netherlands & $* * *<\mathbf{0 . 0 0 0 1}$ & $* * * 0.0002$ & $* * *<\mathbf{0 . 0 0 0 1}$ & 0.6258 \\
\hline Germany & $* * *<\mathbf{0 . 0 0 0 1}$ & $* * * 0.0058$ & $* * *<\mathbf{0 . 0 0 0 1}$ & $* * 0.0485$ \\
\hline Italy & $* * *<\mathbf{0 . 0 0 0 1}$ & $* * *<0.0001$ & $* * *<\mathbf{0 . 0 0 0 1}$ & 0.4968 \\
\hline Spain & $* * *<\mathbf{0 . 0 0 0 1}$ & $* * *<0.0001$ & $* * *<\mathbf{0 . 0 0 0 1}$ & 0.3161 \\
\hline France & $* * *<\mathbf{0 . 0 0 0 1}$ & $* * 0.0132$ & $* * *<\mathbf{0 . 0 0 0 1}$ & 0.2996 \\
\hline $\begin{array}{c}\text { United } \\
\text { Kingdom }\end{array}$ & $* * *<\mathbf{0 . 0 0 0 1}$ & 0.1157 & $* * *<\mathbf{0 . 0 0 0 1}$ & 0.5000 \\
\hline Belgium & $* * *<\mathbf{0 . 0 0 0 1}$ & $* * * 0.0056$ & $* * * \mathbf{0 . 0 0 0 1}$ & $* * * 0.0024$ \\
\hline Poland & $* * *<\mathbf{0 . 0 0 0 1}$ & $* * 0.0431$ & $* * *<\mathbf{0 . 0 0 0 1}$ & 0.5013 \\
\hline
\end{tabular}




\begin{tabular}{ccccc}
\hline \multirow{2}{*}{ Country } & \multicolumn{4}{c}{ Type of tails tested } \\
\cline { 2 - 5 } & Left $\rightarrow$ Left & Left $\rightarrow$ Right & Right $\rightarrow$ Right & Right $\rightarrow$ Left \\
\hline \hline Greece & $* * *<\mathbf{0 . 0 0 0 1}$ & 0.5787 & 0.6988 & $* \mathbf{0 . 0 6 9 7}$ \\
\hline Sweden & $* * *<\mathbf{0 . 0 0 0 1}$ & $* * 0.0251$ & $* * *<\mathbf{0 . 0 0 0 1}$ & 0.9292 \\
\hline Norway & $* * *<\mathbf{0 . 0 0 0 1}$ & $* * * 0.0010$ & $* * *<\mathbf{0 . 0 0 0 1}$ & $* * 0.0224$ \\
\hline
\end{tabular}

Note: $P$-values that indicate a significant test result and a dominant response (smaller $p$ value) are bold. Null hypothesis: Oil returns do not Granger-cause in tails stock market returns.

Source: Author's own calculations.

Table 4 P-values of Granger Contemporaneous and Delayed Causality in Tails Test (Stock Market $\rightarrow$ Oil). Full Sample: 2.01.2008-30.04.2019

\begin{tabular}{ccccc}
\hline \multirow{2}{*}{ Country } & \multicolumn{4}{c}{ Type of tails tested } \\
\cline { 2 - 4 } & Left $\rightarrow$ Left & Left $\rightarrow$ Right & Right $\rightarrow$ Right & Right $\rightarrow$ Left \\
\hline \hline Netherlands & $* * *<\mathbf{0 . 0 0 0 1}$ & $* * * 0.0061$ & $* * *<\mathbf{0 . 0 0 0 1}$ & $* 0.0759$ \\
\hline Germany & $* * *<\mathbf{0 . 0 0 0 1}$ & $* * * 0.0003$ & $* * *<\mathbf{0 . 0 0 0 1}$ & 0.7883 \\
\hline Italy & $* * *<\mathbf{0 . 0 0 0 1}$ & $* * * 0.0011$ & $* * *<\mathbf{0 . 0 0 0 1}$ & 0.6365 \\
\hline Spain & $* * *<\mathbf{0 . 0 0 0 1}$ & $* * 0.0324$ & $* * * \mathbf{0 . 0 0 0 3}$ & 0.3266 \\
\hline France & $* * *<\mathbf{0 . 0 0 0 1}$ & $* * * 0.0085$ & $* * *<\mathbf{0 . 0 0 0 1}$ & 0.1551 \\
\hline United & & $* * * 0.0057$ & & 0.3060 \\
Kingdom & $* * *<\mathbf{0 . 0 0 0 1}$ & & $* * *<\mathbf{0 . 0 0 0 1}$ & \\
\hline Belgium & $* * *<\mathbf{0 . 0 0 0 1}$ & $* * * 0.0001$ & $* * * \mathbf{0 . 0 0 0 3}$ & 0.2442 \\
\hline Poland & $* * *<\mathbf{0 . 0 0 0 1}$ & 0.3759 & $* * *<\mathbf{0 . 0 0 0 1}$ & 0.4633 \\
\hline Greece & $* * *<\mathbf{0 . 0 0 0 1}$ & $* * * 0.0033$ & 0.2016 & 0.2408 \\
\hline Sweden & $* * *<\mathbf{0 . 0 0 0 1}$ & $* 0.0583$ & $* * *<\mathbf{0 . 0 0 0 1}$ & 0.6004 \\
\hline Norway & $* * *<\mathbf{0 . 0 0 0 1}$ & 0.1089 & $* * *<\mathbf{0 . 0 0 0 1}$ & $* * * 0.0001$ \\
\hline
\end{tabular}

Note: $P$-values that indicate a significant test result and a dominant response (smaller $p$ value) are bold. Null hypothesis: Stock market returns do not Granger-cause in tails oil market returns.

Source: Author's own calculations.

Next, we verify if only delayed causality between selected variables is significant. Table 5 shows $p$-values of Candelon and Tokpavi (2016) test, with null hypothesis, that extreme oil returns (left or right tail) did not precede extreme returns on the stock market. Table 6 shows testing results when direction of causality is reversed. Interestingly, in most cases for both directions of causality more long-lasting reactions occurred as a result of negative news from the market. This may be related to a known "negativity bias": investors pay more attention to negative 
extreme returns than positive ones (Reyes, 2018). Our results show that possibility to forecast oil or stock market price changes is much stronger when the market is in crisis.

In some cases, we detected the occurrence of a "rebound effect": after a decline on the day when the price of oil was extremely low (symmetrical instantaneous reaction), the index probably returned to previous values in the following days (delayed asymmetrical effect). On the other hand, in the case of the Netherlands, Italy, Spain, France, and Sweden, we received a reasonable lagged effect of negative news from oil market, since there should be a significant negative relationship between oil price movements and stock returns for oil-importing countries.

Table 5 P-values of Granger Delayed Causality in Tails Test (Oil $\rightarrow$ Stock Market). Full sample: 2.01.2008-30.04.2019

\begin{tabular}{ccccc}
\hline \multirow{2}{*}{ Country } & \multicolumn{4}{c}{ Type of tails tested } \\
\cline { 2 - 5 } & Left $\rightarrow$ Left & Left $\rightarrow$ Right & Right $\rightarrow$ Right & Right $\rightarrow$ Left \\
\hline \hline Netherlands & 0.1149 & $* * * \mathbf{0 . 0 0 2 1}$ & 0.9371 & 0.9420 \\
\hline Germany & $* * *<\mathbf{0 . 0 0 0 1}$ & $* * 0.0129$ & 0.4397 & 0.7441 \\
\hline Italy & $* * * 0.0012$ & $* * *<\mathbf{0 . 0 0 0 1}$ & $* \mathbf{0 . 0 8 1 6}$ & 0.8826 \\
\hline Spain & $* 0.0605$ & $* * *<\mathbf{0 . 0 0 0 1}$ & 0.8256 & 0.6743 \\
\hline France & 0.4383 & $* \mathbf{0 . 0 8 2 0}$ & 0.9064 & 0.7431 \\
\hline United & & & & \\
Kingdom & 0.2674 & 0.2249 & 0.2712 & 0.9296 \\
\hline Belgium & 0.6569 & 0.1034 & 0.9258 & 0.1925 \\
\hline Poland & $* * * \mathbf{0 . 0 0 0 7}$ & $* * 0.0125$ & 0.9368 & 0.7943 \\
\hline Greece & 0.2679 & 0.8777 & 0.7719 & 0.1111 \\
\hline Sweden & 0.4522 & $* \mathbf{0 . 0 7 4 5}$ & 0.8590 & 0.9611 \\
\hline Norway & $* * *<\mathbf{0 . 0 0 0 1}$ & $* * 0.0420$ & 0.8821 & 0.3860 \\
\hline
\end{tabular}

Note: $P$-values that indicate a significant test result and a dominant response (smaller $p$ value) are bold. Null hypothesis: Oil returns do not Granger-cause in tails stock market returns.

Source: Author's own calculations.

Table 6 P-values of Granger delayed causality in tails test (Stock market $\rightarrow$ Oil).

Full sample: 2.01.2008-30.04.2019

\begin{tabular}{ccccc}
\hline \multirow{2}{*}{ Country } & \multicolumn{4}{c}{ Type of tails tested } \\
\cline { 2 - 5 } & Left $\rightarrow$ Left & Left $\rightarrow$ Right & Right $\rightarrow$ Right & Right $\rightarrow$ Left \\
\hline \hline Netherlands & $* * * \mathbf{0 . 0 0 4 2}$ & $* * 0.0236$ & 0.9560 & 0.4191 \\
\hline Germany & $* * * \mathbf{0 . 0 0 0 6}$ & $* 0.0553$ & 0.8200 & 0.9746 \\
\hline Italy & 0.1164 & $* * * \mathbf{0 . 0 0 4 0}$ & 0.9814 & 0.7092 \\
\hline
\end{tabular}




\begin{tabular}{ccccc}
\hline \multirow{2}{*}{ Country } & \multicolumn{4}{c}{ Type of tails tested } \\
\cline { 2 - 5 } & Left $\rightarrow$ Left & Left $\rightarrow$ Right & Right $\rightarrow$ Right & Right $\rightarrow$ Left \\
\hline \hline Spain & $* * * \mathbf{0 . 0 0 0 1}$ & 0.1025 & 0.9525 & 0.3980 \\
\hline France & $* * * \mathbf{0 . 0 0 0 6}$ & $* * 0.0458$ & 0.9127 & 0.5485 \\
\hline United & 0.2674 & $* * \mathbf{0 . 0 2 0 3}$ & 0.6920 & 0.5441 \\
Kingdom & & & & 0.2442 \\
\hline Belgium & $* 0.0876$ & $* * \mathbf{0 . 0 2 0 6}$ & 0.9538 & 0.4210 \\
\hline Poland & 0.3638 & 0.6628 & 0.1193 & 0.5118 \\
\hline Greece & 0.9423 & $* * * \mathbf{0 . 0 0 2 8}$ & 0.1686 & 0.9096 \\
\hline Sweden & $* * *<\mathbf{0 . 0 0 0 1}$ & $* * 0.0199$ & 0.8245 & $* * * \mathbf{0 0 3 7}$ \\
\hline Norway & $* * *<\mathbf{0 0 0 1}$ & 0.7528 & 0.8981 & $*$
\end{tabular}

Note: $P$-values that indicate a significant test result and a dominant response (smaller $p$ value) are bold. Null hypothesis: Stock market returns do not Granger-cause in tails oil market returns.

Source: Author's own calculations.

\section{Conclusions}

An extreme risk spillover test between crude oil and main European stock markets is applied in this article. The test checks the existence of a lead-lag relationship between the occurrence of extremely high or low returns. Our study is an extension of the existing research on European stock market - crude oil relation. Testing results shed some light on the issue. First of all, we found that there is a bidirectional instantaneous symmetrical causality in risk between analyzed series. Secondly, we detected the "negativity bias": investors pay more attention to the negative news. Testing results show that more long-lived reactions appeared as a result of bad news from the oil market and from the stock markets. Our results can help market participants to get better forecasts and reveal an important feature of crude oil on the European stock market.

\section{References}

Arouri, M. (2011). Does Crude Oil Move Stock Markets in Europe? A Sector Investigation. Economic Modelling, vol. 28, pp. 1716-1725. DOI: 10.1016/j.econmod.2011.02.039

Arouri, M. et al. (2012). On the Impacts of Oil Price Fluctuations on European Equity Markets: Volatility Spillover and Hedging Effectiveness. Energy Economics, vol. 34, pp. 611-617. DOI: 10.1016/j.eneco.2011.08.009

Basher, S.A. et al. (2018).The Impact of Oil-market Shocks on Stock Returns in Major Oil-exporting Countries. Journal of International Money and Finance, vol. 86, pp. 264-280. DOI: 10.1016/j.jimonfin.2018.05.003 
BP (2018). BP Statistical Review of World Energy. Retrieved from https://www.bp.com/content/dam/bp/business-

sites/en/global/corporate/pdfs/energy-economics/statistical-review/bp-statsreview-2018-full-report.pdf

Candelon, B. and Tokpavi, S. (2016). A Nonparametric Test for Granger Causality in Distribution With Application to Financial Contagion. Journal of Business and Economic Statistics, 34(2), pp. 240-253. DOI: 10.1080/07350015.2015.1026774

Cheung, Y.W. and Ng, L.K. (1996). A Causality-in-Variance Test and its Application to Financial Market Prices. Journal of Econometrics, vol. 72, pp. 33-48. DOI: 10.1016/0304-4076(94)01714-X

Hong, Y. (2001). A Test for Volatility Spillover with Application to Exchange Rates. Journal of Econometrics, vol. 103, pp. 183-224. DOI: 10.1016/S03044076(01)00043-4

Hong, Y. et al. (2009). Granger Causality in Risk and Detection of Extreme Risk Spillover between Financial Markets. Journal of Econometrics, vol. 150, pp. 271287. DOI: $10.1016 /$ j.jeconom.2008.12.013

Huang, R.D. et al. (1996). Energy Shocks and Financial Markets. The Journal of Futures Markets, vol. 16, pp. 1-27. DOI: 10.1002/(SICI)10969934(199602)16:1<1::AID-FUT1>3.0.CO;2-Q

Jammazi, R. et al. (2017). Time-varying Causality Between Crude Oil and Stock Markets: What Can We Learn from a Multiscale Perspective? International Review of Economics and Finance, vol. 49, pp. 453-483. DOI: 10.1016/j.iref.2017.03.007

Jones, CH.M. and Kaul, G. (1996). Oil and the Stock Markets. Journal of Finance, vol. 51, pp. 463-493. DOI: $10.2307 / 2329368$

Maghyereh, I. et al. (2016). The Directional Volatility Connectedness Between Crude Oil and Equity Markets: New Evidence from Implied Volatility Indexes. Energy Economics, vol. 57, pp. 78-93. DOI: 10.1016/j.eneco.2016.04.010

Park, J. and Ratti, R.A. (2008). Oil Price Shocks and Stock Markets in the U.S. and 13 European Countries. Energy Economics, vol. 30, pp. 2587-2608. DOI: 10.1016/j.eneco.2008.04.003

Reyes, T. (2019). Negativity Bias in Attention Allocation: Retail Investors' Reaction to Stock Returns. International Review of Finance, vol. 19, pp. 155-189. DOI: 10.1111 /irfi. 12180

Sadorsky, P. (1999). Oil Price Shocks and Stock Market Activity. Energy Economics, vol. 21, pp.449-469. DOI: 10.1016/S0140-9883(99)00020-1

Śmiech, S. and Papież, M. (2013). Fossil Fuel Prices, Exchange Rate, Stock Market: A Dynamic Causality Analysis on the European Market. Economics Letters, vol. 118, pp. 199-202. DOI: 10.1016/j.econlet.2012.10.010 
Wanat, S. et al. (2015). Causality in Distribution between European Stock Markets and Commodity Prices: Using Independence Test Based on the Empirical Copula. In: Jajuga, K. and Ronka-Chmielowiec, W. (eds), Financial Investments and Insurance - Global Trends and the Polish Market. Research Papers of Wrocław University of Economics, vol. 381, pp. 439-454. DOI: 10.15611/pn.2015.381.32

Wang et al. (2013). Oil Price Shocks and Stock Market Activities: Evidence from Oil-importing and Oil-exporting Countries. Journal of Comparative Economics, vol. 41, pp. 1220-1239. DOI: 10.1016/j.jce.2012.12.004

Zhang, D. (2017). Oil Shocks and Stock Markets Revisited: Measuring Connectedness from a Global Perspective. Energy Economics, vol. 62, pp. 323-333. DOI: 10.1016/j.eneco.2017.01.009. 